\title{
3D Sequential Spacal and Thermal Measurements
}

\author{
Lifong ZOU ${ }^{1 *}$, Farida FORTUNE ${ }^{2}$, E CALCIOLARI $^{3} ; \mathrm{N} \mathrm{GKRANIAS}^{4}$, N MARDAS ${ }^{5}, \mathrm{~N} \mathrm{DONOS}^{6}$ \\ Bart's and The London School of Medicine and Dentistry, \\ Queen Mary University of London (QMUL), UK
}

\begin{abstract}
Medical thermography has become ever more accessible for the healthcare provision, due to the combination of easier operation and the lower cost of thermal cameras from the newer production. This has encouraged more applications of thermal imaging in hospitals and medical research laboratories. This study describes a non-invasive three dimensional spacal and thermal imaging system (3dMD) that was certified by the national measurement institute - NPL, and the analytical methodology for volume and temperature measurements over the same region of interest (ROI), and yet this ROI was transited through a sequential pre-registered images, in order to guarantee the measurement of changes were taken from the same location with the same boundary over a sequential subtracted imges. A clinical case was given as an example to demonstrate the effectiveness of this proposed methodology.
\end{abstract}

Key words: 3D spacal image, 3D visual image, 3D thermal image, volume measurement, and sequential measurement

\section{Introduction}

Thermal imaging has become ever more accessible in the healthcare provision, due to it is getting easier to use and the cost has become lower for the newer production of thermal cameras. A range of thermal imaging application currently in use at hospitals and medical research institutions and laboratories. Such as: the prevention of diabetic foot ulceration (G Machin etc. 20217), the measurement of changes in breast cancer-related lymphoedema during reflexology (JA Whatley etc. 2020), improvement of clinical decision making of wound tissue treatment (Keenan E etc. 2017), used as a screening tool for paediatric wrist fractures (Reed C etc. 2020), and screening the joint inflammation and rheumatoid arthritis in children (R Lasanen etc 2015), the detection of active bone lesions in extremities of children with Chronic Nonbacterial Osteomyelitis (Zhao Y,2019), effectively evaluating musculoskeletal disorders for dentists (Cosoroaba MR etc. 2019), for clinical assessment of lesion activity on root surfaces via dehydration (Yang VB etc. 2020) and so forth.

However, the credibility of thermal imaging in medicine is subject to critical use of the technology and proper understanding of thermal physiology. The International Standards Organization has published two documents defining the use of a thermal imaging camera for fever screening. The first document published in September 2008 (IEC 2008) describes the essential design and performance characteristics of a radiometric infrared camera for screening, and the second published in March 2009 defines the recommended mode of deployment including the testing of the system and the training of its users (ISO 2009). This study has followed the good practice suggestions by the national measurement institution - National Physical Laboratory (NPL).

1. Clinical Senior Lecturer in imaging, Centre for Oral Bioengineering, The Institute of Dentistry, Bart's and The London School of Medicine and Dentistry, Queen Mary University of London;

2. Professor of Medicine in relation to Oral Health, Lead of Centre for Immunobiology \& Regenerative Medicine, The Institute of Dentistry, Bart's and The London School of Medicine and Dentistry, Queen Mary University of London;

3. Clinical Senior Lecturer in translational Dental Medicine; Centre for Oral Clinical Research, The Institute of Dentistry, Bart's and The London School of Medicine and Dentistry, Queen Mary University of London;

4. Senior Clinical Lecturer, Centre for Oral Clinical Research, The Institute of Dentistry, Bart's and The London School of Medicine and Dentistry, Queen Mary University of London;

5. Clinical Reader in Periodontology, Centre for Oral Clinical Research, The Institute of Dentistry, Bart's and The London School of Medicine and Dentistry, Queen Mary University of London;

6. Clinical Professor and Chair of periodontology and Implant Dentistry, Lead of Centre for Oral Clinical Research and Director of Research. The Institute of Dentistry, Bart's and The London School of Medicine and Dentistry, Queen Mary University of London

* Correspondent author: Lifong Zou, Clinical Senior Lecturer in imaging, Life Surface Imaging Facility, Centre for Oral Bioengineering, The Institute of Dentistry, Bart's and The London School of Medicine and Dentistry, Queen Mary University of London; Email: 1.zou@qmul.ac.uk; Tel: +44 (0) 207882 8624; Address: Office 4; on the 4th Floor, Institute of Dentistry/Dental Hospital Building, Turner Street, London E1 2AD; UK 
This study describes a 3D spacal and thermal image system, that was evaluated against standard blackbody by NPL and certified by NPL, to achieve a demonstrably traceable, accurate, and reliable temperature output. A pair of thermal cameras were integrated to an existing facial scanning system 3dMDface.t by a group of professionals from 3dMD and QMUL, that formed a new system to capture 3D spacal and thermal image at the same time, the captured data were analysed using a modified version of 3dMDvultus software package; and an analytical methodology were established to measure the volumes and temperatures at the same region of interest that transit through a sequential preregistered images, in order to quantify the changes at the same location with the same boundary. A clinical case was given as an example to demonstrate the effectiveness of this proposed methodology.

\section{Materials and Methods}

Volume measurements of a sequential life surface images is challenging (Zou L etc. 2018), due to the irregularity of life surface, and the control of the ambient condition for thermal image measurements, moreover to guarantee the measurements were taken at the same location over consecutive images. The methodology proposed in this study has two common regions for measurements: The region of interest $(\mathrm{ROI})$ for volume measurement and points of interest $(\mathrm{POI})$ for temperature measurement.

The challenge of this study was (1) identify the region of interest(ROI) over an irregular surface, therefore this ROI was a free form surface that was "drawn by hand"; (2) the ROI and and Points of interest (POI) needed to be transit to consecutive subtracted images to provide the multiple correlations: The spacal correlations for the volume measurement that was guaranteed to be taken over the same area at the same location and with the same boundary; also the ROI and POI were transited from the consecutive spacal image to the consecutive thermal images.

\section{Equipment}

Two thermal cameras (FLIR T1030 Sc28ㅜㄹ, Research IR Max, Glove) were integrated to 3dMDface.t (3dMD, USA), the image analytical software package is 3dMDvultus (3dMD, USA).

\section{Device traceability, Calibration and uncertainty}

The critical performance parameters of the imaging system were assessed against qualified blackbody reference sources from National Measurement Institute - the National Physical Laboratory (NPL, UK) where host the nationally highest standard. The performance assessments include time to stabilisation from switch on (warm up time), the size of source effect (SSE), temperature calibration range from 35 ${ }^{\circ} \mathrm{C}$ to $40^{\circ} \mathrm{C}$, and the total uncertainty was $0.55^{\circ} \mathrm{C}(\mathrm{k}=2)$.

\section{Clinical sitting}

The clinical sitting and the patient preparation was adapted and followed the standard procedures for infrared imaging in medicine by Ring EF and Ammer K (2012).

\section{Consecutive images and analysis}

\subsection{Surface registration}

The registration of consecutive images, the registration process applied Iterative Closest Point(ICP) algorithm to the region of forehead and the temporal region where were geometrically remain unchanged in the duration of the study, also the area provided the 3D geometrical features for the registration process. The registration differences were between $0.12 \mathrm{~mm}$ to $0.17 \mathrm{~mm}$ as RMS values. 


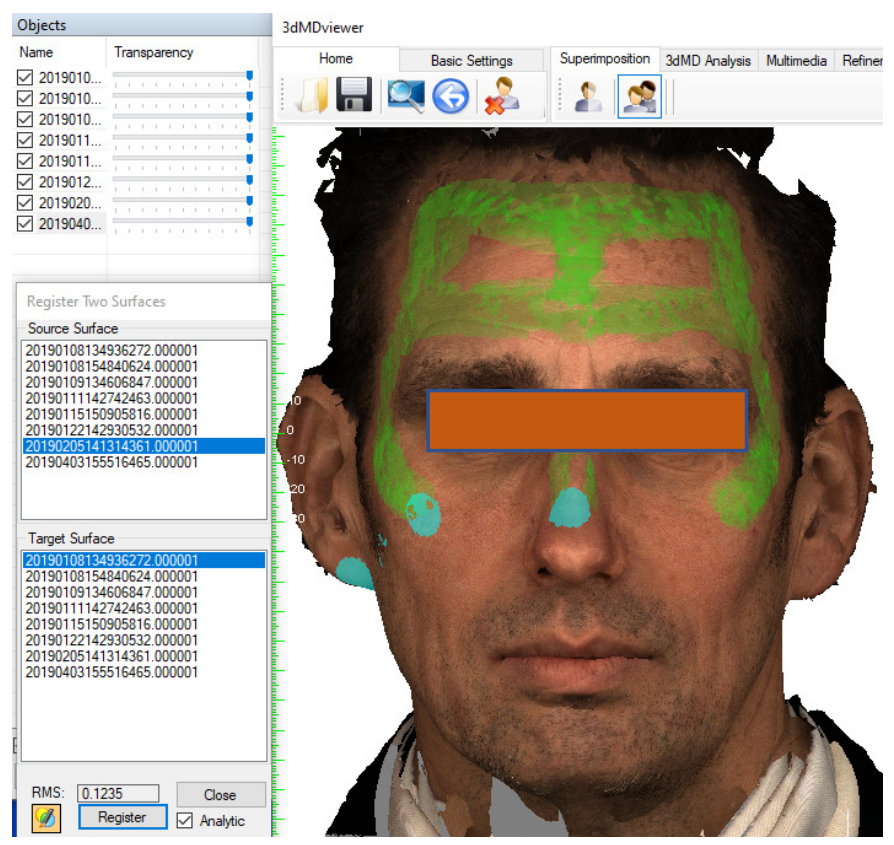

Figure 1: Eight consecutive images to be superimpose. Seven of them were registered on the baseline image using ICP algorithm applied on the geometrical stable region where highlighted by green colour of forehead and temporal areas.

\subsection{Define the Region of Interest (ROI) and Points of interest (POI)}

Seven individually registered images were subtracted from the baseline image. A colour coded image were mapped and the depth differences along the vectors of the surface points were presented by different colour shades shown by the colour scale in Figure 2. The area with positive values represent the region where swelling occurred (red and purple colours), that defined as $\mathrm{ROI}$, its boundary was the nearest surroundings where the subtraction values were zero or close to zero $(+/-0.2 \mathrm{~mm})$ where were in blue colour in Figure 2.

Within the ROI, 8 points were evenly distributed for temperature measurement. The detection of temperature to be at the level of sub-degree centigrade was challenged by the environmental fluctuation in temperature. To eliminate such noise from the environment, a set of point was selected, that mirrored to the opposing side of the face as the control temperature which was taken into consideration at the temperature measurement.

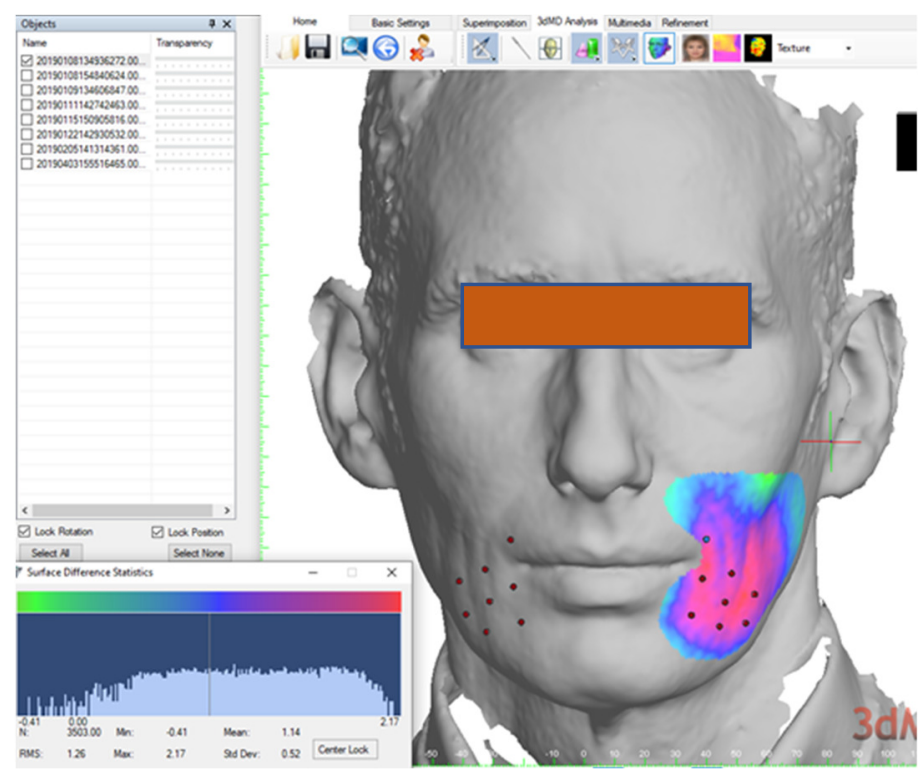

Figure 2: The definition of region of interest (ROI) for volume measurement, the definition of point of interest (POI) and the self-control temperature for the measurement. 


\subsection{Transit the POI from spacal image to the thermal image for correlated measurements throughout the consecutive thermal images}

The definition of $\mathrm{POI}$ which now included the two sets of points the original set of $\mathrm{POI}$ and the control set of POI, were transit to all other superimposed thermal images, as the position markers to obtain the temperature readings, the final temperature measurement was the average value from the surgical site (left in this case) subtracted from the average temperature of the control site (right site in this case).

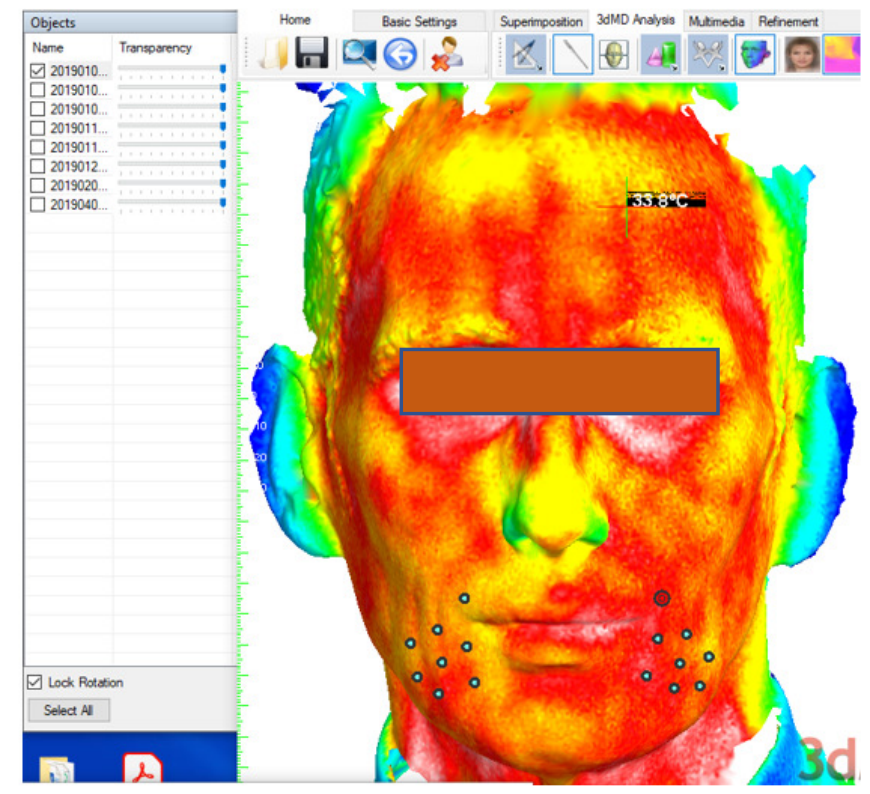

Figure 3: The POI on the surgical (left) and control (right) sites were transited from the spacal images to the thermal images that guaranteed the measurements were taken at the same locations throughout consecutive images.

\section{A clinical case}

The healing process is critical for the recovery and prognosis of a surgical treatment in dentistry. Monitoring the temperature changes at the surgical site provides biological markers that could reflect the progression of the healing process. This study using facial imaging technique captures spacal and thermal 3D life surface images at sequential time points at pre-surgery, post-surgery, one, three, seven, fourteen, thirty and sixty days post-surgery. The analysis and measurements of these consecutive images reveals the spacal and thermal changes on the faces. The spacal changes represent the swollen of the soft tissue and the thermal changes provide indications of the biological and physiological changes.

The consecutive images were taken before and after a surgery. The baseline image was the image taken before the surgery (V3 PreOp), followed by 7 other images were taken at the time points immediately after the surgery (V3 PostOp) on the same day to the baseline, the one day (V4), three days (V5), seven days (V6), fourteen days(V7), thirty days (V8) and sixty days (V9) after the surgery. These images were analysed using 3D geometrical and thermal image analytical software package 3dMDvultus. 
Table 1: Images taken at different time points (V3 post-Op, V4, V5, V6, V7, V8, V9) are all individually superimposed to the baseline image V3PreOp, the linear measurements results of maximum, minimum and mean difference, and volume measurements were listed:

\begin{tabular}{|c|c|c|c|c|c|c|c|c|}
\hline $\begin{array}{l}\text { File Name: } \\
006 \text { TP }\end{array}$ & $\begin{array}{l}\text { V3 } \\
\text { PreOp }\end{array}$ & $\begin{array}{l}\text { V3 } \\
\text { PostOp }\end{array}$ & V4 & V5 & V6 & V7 & V8 & V9 \\
\hline & 08Jan19 & 08Jan19 & 09Jan19 & 11Jan19 & 15Jan19 & 22Jan19 & 05Feb19 & 03Apr19 \\
\hline \multicolumn{9}{|l|}{$\begin{array}{l}\text { 3D spacel } \\
\text { Images }\end{array}$} \\
\hline & & & & & & & & \\
\hline $\begin{array}{l}\text { ROI used for } \\
\text { measures }\end{array}$ & & $=$ & 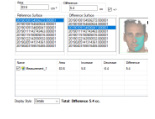 & $E=$ & -9 & $=-2$ & $=-1$ & $=\frac{2}{2}$ \\
\hline $\begin{array}{l}\text { Maximum } \\
\text { Depth }(\mathrm{mm})\end{array}$ & & 2.4 & 2.84 & 2.73 & 3.17 & 3.51 & 1.06 & 0.86 \\
\hline $\begin{array}{l}\text { Minimum } \\
\text { Depth }(\mathrm{mm})\end{array}$ & & -0.5 & -1.32 & -1.48 & -1.89 & -2.04 & -1.51 & -1.03 \\
\hline $\begin{array}{l}\text { Mean Depth } \\
(\mathrm{mm})\end{array}$ & & 0.8 & 0.68 & 0.52 & 0.48 & 0.34 & -0.05 & 0.29 \\
\hline $\begin{array}{l}\text { SD Depth } \\
(\mathrm{mm})\end{array}$ & & 0.66 & 0.81 & 0.88 & 0.85 & 0.90 & 0.39 & 0.04 \\
\hline RMS & & 1.0 & 1.06 & 1.02 & 0.98 & 0.96 & 0.39 & 0.29 \\
\hline $\begin{array}{l}\text { Volume } \\
\text { (cm3) }\end{array}$ & & 6.6 & 5.8 & 5.4 & 4.5 & 4.1 & 0.9 & 1.2 \\
\hline
\end{tabular}


Table 2: Images taken at different time points (V3 post-Op, V4, V5, V6, V7, V8, V9) are all individually superimposed to the baseline image V3PreOp, the linear measurements results of maximum, minimum and mean difference, and volume measurements were listed:

\begin{tabular}{|c|c|c|c|c|c|c|c|c|}
\hline $\begin{array}{l}\text { File Name: } \\
006 \text { TP }\end{array}$ & V3 PreOp & $\begin{array}{l}\text { V3 } \\
\text { PostOp }\end{array}$ & V4 & V5 & V6 & V7 & V8 & V9 \\
\hline $\begin{array}{l}\text { Dates of } \\
\text { image taken }\end{array}$ & 8Jan19 & 8Jan19 & 9Jan19 & 11Jan19 & 15Jan19 & 22Jan19 & 5 Feb19 & 3Apr19 \\
\hline $\begin{array}{l}\text { 3D Thermal } \\
\text { Images }\end{array}$ & $\sqrt{6}$ & $(9)$ & 8 & 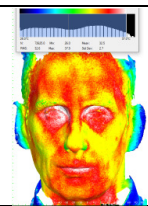 & $(x)$ & (x) & $\left(\cos ^{1}\right)$ & $\left\{\begin{array}{l}0 \\
0\end{array}\right.$ \\
\hline $\begin{array}{l}\text { Left } \\
\text { Labiomadibula } \\
\mathrm{r} \text { fold } \mathrm{PT} 1^{\circ} \mathrm{C}\end{array}$ & 34.4 & 32.7 & 32.1 & 34.7 & 34.5 & 34.7 & 32.6 & 32.8 \\
\hline Left PT2 ${ }^{\circ} \mathrm{C}$ & 34.6 & 33.4 & 33.4 & 34.5 & 34.4 & 34.8 & 33.6 & 32.9 \\
\hline Left PT3 ${ }^{\circ} \mathrm{C}$ & 33.6 & 32.7 & 32.4 & 33.6 & 33.6 & 33.6 & 31.6 & 31.7 \\
\hline Left PT4 ${ }^{\circ} \mathrm{C}$ & 34.7 & 32.9 & 32.0 & 34.3 & 34.3 & 34.0 & 32.6 & 32.4 \\
\hline Left PT5 ${ }^{\circ} \mathrm{C}$ & 34.6 & 33.3 & 33.2 & 34.9 & 34.6 & 34.8 & 33.6 & 32.9 \\
\hline Left PT6 ${ }^{\circ} \mathrm{C}$ & 33.8 & 32.4 & 32.4 & 33.8 & 33.4 & 33.1 & 31.4 & 31.6 \\
\hline Left PT7 ${ }^{\circ} \mathrm{C}$ & 34.0 & 32.8 & 32.0 & 34.4 & 33.7 & 33.8 & 31.9 & 32.0 \\
\hline Left PT8 ${ }^{\circ} \mathrm{C}$ & 32.9 & 32.7 & 32.1 & 32.0 & 33.3 & 33.2 & 31.7 & 31.5 \\
\hline $\begin{array}{l}\text { Mean on } \\
\text { surgical } \\
\text { site }\left({ }^{\circ} \mathrm{C}\right) \\
\end{array}$ & 34.2 & 32.8 & 32.5 & 34.0 & 33.9 & 34 & 32.3 & 32.2 \\
\hline $\begin{array}{l}\text { SD on surgical } \\
\text { site }\left({ }^{\circ} \mathrm{C}\right)\end{array}$ & 0.4 & 0.3 & 0.5 & 0.9 & 0.5 & 0.7 & 0.8 & 0.5 \\
\hline $\begin{array}{l}\text { Right } \\
\text { Labiomadibula } \\
\text { r fold PT1 }{ }^{\circ} \mathrm{C}\end{array}$ & 33.4 & 32.6 & 32.1 & 33.7 & 33.6 & 33.7 & 31.3 & 31.1 \\
\hline Right PT2 ${ }^{\circ} \mathrm{C}$ & 34.5 & 34.1 & 33.1 & 34.5 & 34.0 & 34.5 & 32.5 & 32.3 \\
\hline Right $\mathrm{PT} 3{ }^{\circ} \mathrm{C}$ & 33.5 & 32.2 & 31.8 & 33.2 & 32.5 & 33.6 & 31.4 & 31.4 \\
\hline Right PT4 ${ }^{\circ} \mathrm{C}$ & 33.6 & 32.1 & 32.4 & 34.3 & 33.0 & 33.8 & 30.9 & 31.8 \\
\hline Right PT5 ${ }^{\circ} \mathrm{C}$ & 33.7 & 32.4 & 32.4 & 32.9 & 32.8 & 33.0 & 30.7 & 31.4 \\
\hline Right PT $6{ }^{\circ} \mathrm{C}$ & 33.3 & 32.6 & 32.1 & 33.7 & 33.4 & 33.6 & 31.2 & 31.1 \\
\hline Right PT7 ${ }^{\circ} \mathrm{C}$ & 34.5 & 33.1 & 32.3 & 34.4 & 33.6 & 33.8 & 32.1 & 32.2 \\
\hline Right PT8 ${ }^{\circ} \mathrm{C}$ & 33.4 & 32.2 & 31.8 & 33.3 & 32.5 & 33.6 & 31.4 & 31.1 \\
\hline $\begin{array}{l}\text { Mean on } \\
\text { control site }\left({ }^{\circ} \mathrm{C}\right)\end{array}$ & 33.7 & 32.6 & 32.1 & 33.7 & 33.1 & 33.7 & 31.3 & 31.6 \\
\hline $\begin{array}{l}\text { SD on control } \\
\text { site }\left({ }^{\circ} \mathrm{C}\right)\end{array}$ & 0.4 & 0.8 & 0.2 & 0.7 & 0.6 & 0.5 & 0.7 & 0.4 \\
\hline $\begin{array}{l}\text { The } \\
\text { temperature } \\
\text { changes }\left({ }^{\circ} \mathrm{C}\right)\end{array}$ & +0.5 & +0.2 & +0.4 & +0.3 & +0.8 & +0.3 & +1.0 & +0.6 \\
\hline
\end{tabular}




\section{Discussions}

The volume measurement demonstrated a clear trend of a good healing process as the swelling volume was consistently reduced over the time from Visit 1 to visit 9, while the temperature measurement did not correlate well to such trend. The temperature measurement appeared to be more challenging. First of all, the points of interest was based on numbers of points, which bound to have larger random error compared to area based volume measurement, despite the points were transited, but it not necessarily picked up the most representative temperature, if an area can be used such randomisation could be largely eliminated; secondly the ambient or noise control requests more investigation due to the fact that the core temperature at different times (early morning or late afternoon), conditions of health and seasons of the year (Jan to Apr in this case) caused the fluctuation of body temperature which were independent from the surgery effect, which need to be eliminated, the next stage of the study will be focused on the way of eliminations.

\section{Conclusions}

The dual modality imaging has the potential of providing more biological and pathological information however a further investigation is requested.

\section{Acknowledgements}

Bart's Charity, 3dMD and NPL

\section{References}

IEC 2008 Medical electrical equipment-part 2-59: particular requirements for the basic safety and essential performance of screening thermographs for human febrile temperature screening IEC 806012-59, Ed. 1.0

ISO/TR 2009 Medical electrical equipment-deployment, implementation and operational guidelines for identifying febrile humans using a screening thermograph ISO/TR 13154:2009

Ring E F J and Ammer K (2012); Infrared thermal imaging in medicine; Physiological Measurement, 33 R33;

Machin G, Whittam A, Ainarkar S, Allen J, Bevans J, Edmonds M, Kluwe B, Macdonald A, Petrova N, Plassmann P, Ring F, Rogers $L$ and Simpson R (2017); A medical thermal imaging device for the prevention of diabetic foot ulceration; Physiological Measurement, 38:420-430;

Ring EF and Ammer K (2012); Standard procedures for infrared imaging in medicine. In: Medical infrared imaging. Diakides NA, Bronzino JD, eds. Boca Raton: CRC Press;

Fulbrook P (1997), Core body temperature measurement: a comparison of axilla, tympanic membrane and pulmonary artery blood temperature, Intensive and Critical Care Nursing, 1997, 13, p266-p272;

Cosoroaba MR, Cirin L, Anghel MD, Talpos-Niculescu CI, Argesanu V, Farkas AZ, Negrutiu ML.J (2019); The use of thermal imaging in evaluating musculoskeletal disorders in dentists. Med Life. 2019 Jul-Sep;12(3):247-252.

Yang VB, Chang NY, Fried D (2020); A thermal imaging handpiece for the clinical assessment of lesion activity on root surfaces via dehydration. .Proc SPIE Int Soc Opt Eng. 2020 Feb;11217:11217.

Keenan E, Gethin G, Flynn L, Watterson D, O'Connor GM. Enhanced thermal imaging of wound tissue for better clinical decision making. Physiol Meas. 2017 Jun;38(6):1104-1115.

Whatley JA, Kay S.Br J Using thermal imaging to measure changes in breast cancer-related lymphoedema during reflexology. Community Nurs. 2020 Oct 1;25(Sup10):S6-S11.

Reed C, Saatchi R, Burke D, Ramlakhan S (2020); Infrared thermal imaging as a screening tool for paediatric wrist fractures..Med Biol Eng Comput. 2020 Jul;58(7):1549-1563.

Lasanen R, Piippo-Savolainen E, Remes-Pakarinen T, Kröger L, Heikkilä A, Julkunen P, Karhu J, Töyräs (2015), Thermal imaging in screening of joint inflammation and rheumatoid arthritis in children. J.Physiol Meas. 2015 Feb;36(2):273-82.

Zhao Y, lyer RS, Reichley L, Oron AP, Gove NE, Kitsch AE, Biswas D, Friedman S, Partridge SC, Wallace CA (2019). A Pilot Study of Infrared Thermal Imaging to Detect Active Bone Lesions in Children With Chronic Nonbacterial Osteomyelitis. Arthritis Care Res (Hoboken). 2019 Nov;71(11):1430-1435.

Zou L, Richard R, Blythe J, Donos N (2018), Challenges with Life Surface Imaging; Conference Proceedings of 3D Body.Tech Conference 2018 published by Collegio 28, CH-6612 Ascona, Switzerland; Open source for abstracts and papers: www.3dbody.tech/cap 